\title{
Somos imagem: 0 mundo é imagem
}

\section{We are image: the world is image}

Resumo: O presente artigo trata de problematizar o conceito de imagem a luz, principalmente, de Henry Bergson e Gilles Deleuze. O objetivo é localizar a imagem em sua complexidade, discutindo-a relacionada aos conceitos de afecção e duração. Teremos, pois o corpo como imagem de referencia e mediação das imagens do mundo. Assim, torna-se possível inscrevê-la para além da representação e do duplo como, tradicionalmente, vem sendo compreendida. Nesta escrita a imagem não é fixa: é matéria em movimento e convocação para o pensamento desviar-se de noções de unidade e origem.

Palavras-chave: I magem. Afecção. Duração. Corpo.

Abstract: This article treats to problematize the concept of image to light, especially of Henry Bergson and Gilles Deleuze. The objective is to locate the image in its complexity, it discusses the related concepts of affection and duration. We have than the body image as a reference and mediation of images of the world. This makes it possible to put it beyond the representation and the double and, traditionally, has been understood. In this article the image is not fixed: it is matter in motion and call for thinking deviate from notions of unity and origin.

Keywords: I mage. Affection. Duration. Body.

KIRST, Patrícia; FONSECA, Tânia Mara Galli. Somos Imagem: o mundo é imagem. Informática na Educação: teoria \& prática, Porto Alegre, v. 11, n. 2 p. 34-38, jul./dez. 2008

\author{
Patrícia Kirst \\ Universidade Federal do Rio Grande do Sul \\ Tânia Mara Galli Fonseca \\ Universidade Federal do Rio Grande do Sul
}

P artiremos da idéia de que a imagem não é um duplo, que não representa, mas que inventa a vida: compõe a matéria em suas tantas velocidades de transformação. É matéria, é memória e é corpo. Através destes pressupostos iniciais estamos conjecturando um modo da imagem escapar do espelho e complicá-la. A imagem não será entendida através da noção identificatória. Neste espeIho não se busca a própria imagem. Aqui, Narciso desencanta de si e escapa da morte.

Tal escape é em direção à transmundos para a produção de uma ciência que se distancie, conscientemente, da verdade e da representação através do uso, associação e atualização de seus conceitos. Tal modo de produzir ciência está ligado à proliferação de correspondências comunicativas descentralizadas das coisas com suas imagens gerando outras imagens que, de tão efêmeras, podem, possivelmente, não receber nome e não encontrar sequer palavra. Conseguir pensar sem a regulação da representação introduz importantes diferenças acerca das impossibilidades de fazer ciência buscando origens e unidades.

Trata-se de pensar a imagem em múltipla conexão com seus fluxos exteriores o que a atravessa e a torna suscetível a sentidos que são passagens e não a verdades e correspon- 
dências lineares. A imagem em seu aspecto efêmero será analisada no decorrer desta escrita, principalmente, com base no conceito de duração em Bergson. Assim, a imagem não é pura e, neste ponto de vista, sua discussão conceitual é entendida como algo vivo e circunscrito em relação a interferências que desfazem e refazem uma ciência que é inventiva e afetada por múltiplos campos de saber. É este o motivo pelo qual intentamos neste artigo ultrapassar a compreensão da imagem como o duplo e representação.

Pensar nas descontinuidades, nos silêncios e nos trancos ou harmonias que podem levar de uma imagem a outra é pensar na imagem em processualidade. É a própria transimagem que, convoca o pensamento para, alegremente, articular novos conceitos que possam lidar com as travessias que não param de recomeçar em linhas de breve memória deixadas sempre para trás, avançando para um horizonte, por vezes, improvável. Não há conceito para este horizonte que é pura indeterminação, e espaço imaginado, assim como uma queda transversal que, faz pouso no meio de um caledoscópio de conceitos, com suas tonalidades investe a subjetividade para um olhar que mais inventa do que entende.

A imagem em processo demarca um pensamento que remete ao impensado, ao desvio da linha por píxels acelerados como no exemplo da imagem em sua face digital. Cabe dizer que o pixel é a menor unidade luminosa que olho humano pode ver. É a molécula da imagem. Estes podem conduzir a vazios, permitindo uma formação abalada e caótica que nos força a pensar: o que viria a ser uma imagem? Não se trata somente de associar formas, cores e filtros possíveis, mais de criar diferenciação e nela dimensionar conveniências.

Na resistência à identidade, à associação direta e à representação, nasce uma metáfora para o pensamento que, se constitui no entreimagens, operando no sentido de desconstruir o uno na produção de conhecimento, na invenção de imagens, na invenção e arranjo de conceitos. Cabe aqui salientar que a idéia de entre-imagens relaciona-se com o conceito de rizoma na filosofia de Gilles Deleuze e Felix Guattari que por sua vez contém a idéia de permanente descentramento: “[...] um rizoma não começa e nem chega a nenhum lugar, ele está sempre no meio, entre as coisas, interser, intermezzo. O rizoma tem por tecido e conjunção e...e...e... capaz de sacudir e desenraizar o verbo ser." (DELEUZE; GUATTARI, 1995, p. 23) O desafio é tentar um exercício transdisciplinar que insiste em criar morada nos espaçamentos e nas brechas que apontam para um corpo mutante para que o pensamento possa fluir conforme as passagens transversais das incertezas de um mundo a ser construído. Necessitamos, para tanto, habitar a indeterminação da imagem e pensála como ferramenta para o agenciamento ${ }^{1}$ da invenção.

Imagem problema, imagem mundo, deserto pregnante de gestos fazendo o corpo ser capaz de cruzar fronteiras invisíveis à espreita, em virtualidade, na paisagem. Plano de composição das existências em instantes congelados, seqüenciados, editados e lembrados conforme o exercício da expressão e das possibilidades de cada mídia. Não sendo aquilo que aparece, por estar em constante mudança, a imagem irradia, sobre si mesma e sobre outras, devires que indicam a finitude das formas e o modo universo: este nunca acaba porque não se fixa e, em suas multiplicações, vai sendo operado.

Experimenta-se a imagem através da afecção ${ }^{2}$, à medida em que, ela fica no corpo variando segundo as navegações impostas pelos encontros. A imagem faz mover o corpo para o desejo e para certa duração. Sobre a relação entre imagem, matéria e corpo, seguem as palavras de Bergson (1999, p. 17): “Chamo de matéria o conjunto de imagens, e de percepção da matéria essas mesmas imagens relacionadas a ação possível de uma certa imagem determinada, meu corpo." Portanto, a imagem referência ou o centro de mediação de todas as imagens é o corpo.

\footnotetext{
1 "Segundo um primeiro eixo, horizontal, um agenciamento comporta dois segmentos, um de conteúdo, outro de expressão. De um lado ele é agenciamento maquínico de corpos, de ações, de paixões, mistura de corpos reagindo uns sobre outros; de outro, agenciamento coletivo de enunciação, de atos e de enunciados, transformações incorpóreas atribuídas aos corpos. Mas, segundo um eixo vertical orientado, o agenciamento tem ao mesmo tempo lados territoriais ou reterritorializados, que o estabilizam, e pontas de desterritorialização que o impelem." (DELEUZE; GUATTARI, 2003, p. 112)

${ }^{2}$ A afecção “[...] é, primeiramente, o vestígio de um corpo sobre o outro, o estado de um corpo que tenha sofrido a ação de um outro corpo" (DELEUZE; GUATTARI, 1997, p. 156); e “[...] não é só um efeito instantâneo de um corpo sobre o meu, mas tem também um feito sobre minha própria duração, prazer ou dor, alegria ou tristeza. São passagens, devires, ascenções e quedas, variações contínuas de potências que vão de um lado ao outro." (DELEUZE; GUATTARI, 1997, p. 157)
} 
A imagem pede: dê-me um corpo. Sua potência virtual atualiza-se para tornar-se outra e integrar as redes de memória. Assim, uma imagem terá tantos sentidos quanto às recombinações de forças de que dela se apropriarem. Entregar a imagem às forças é um trabalho de resistência aos duplos representacionais e as correspondências binomiais.

Os pontos onde a imagem afeta são justamente aqueles em que o corpo resiste e, nesta luta, integra a sua substância algo desta ação. Assim, dá-se a afecção. O sujeito, em sua ação, diminui a distância entre a imagem e seu corpo fazendo o ato de transformar convir com a imagem de si. Localiza-se, então, neste limite ou na extensão de tal encontro, a percepção da imagem. O processo de subjetivação que orienta nossa reflexão é a passagem e variação nos corpos das forças ativas da imagem em seu estado molecular composta por outras imagens menores que habitam o detalhe e que pedem por procura. É importante a referência à variação porque o corpopensamento é subjetivado na medida em que se iguala ao objeto que se expõe, entretanto, o pensamento entra em duplicidade com o objeto de forma parcial, em mediação de intensidades moleculares: o ser igual à diferença e ao sentido. Ou o ser como sentido do mundo, livre de essencialidades. Não há nada para além do pensamento; somos o pensamento que pensamos, neste sentido somos imagem quando por ela nos encontramos imantados em nossas percepções.

Consequentemente, não há separação entre o sujeito que vê e o sentido que insere no visto, o sentido está no ver. Não há um segundo mundo a ser acessado, o sentido é imanente ao objeto. No texto de Deleuze, em Ilha Deserta, relativo Jean Hypoppolite: Lógica e Existência, nos é dito que: “Nada há para se ver atrás da cortina, o segredo é não há segredo [...]" (DELEUZE, 2006, p. 25). Assim, o sentido do objeto é operado pelo corpo que ocasiona o encontro, estando para além do objeto e no encontro durando, vivendo e morrendo. O sentido ou pensamento atravessa a barreira da força e torna-se forma quando acede a diferença gerada pela produção de sentidos.

Suely Rolnik e Felix Guattari (1993) afirmam que a simulação é uma intensidade e também a exteriorização do desejo, cuja intensidade toma uma forma provisória, mas consistente, em matéria e expressão. A forma ideal não existe, o rosto tampouco, a não ser que seja considerado uma sucessão de máscaras. A simulação nada tem a ver com falsidade ou fingimento; é, apenas, uma condutora da intensidade dos afetos, tornandose, então, realidade. A realidade é artifício e, neste sentido, a busca pela verdade se torna um falso problema.

Vê-se que é no artifício e só nele que as intensidades ganham e perdem sentido, produzindose mundos e desmanchando-se outros, tudo ao mesmo tempo. Movimentos de territorialização: intensidades aterrizando em certas matérias de expressão; nascimento de mundos. (ROLNIK; GUATTARI, 1993, p. 23)

O olhar nunca foi passivo. A imagem não vem somente de fora e, certamente, o grau de compreensão de qualquer mensagem se dá na medida em que ela é resignificada e associada com a vida. Se ela não sofre nenhuma modificação ela é apenas um clichê e se processa na ordem da reprodução. A imagem pode ser engendrada em dois tempos pelo menos: enquanto clichê, ligada à certeza e a verdade, e enquanto simulação, relacionada à imagem como intermezzo, como uma nave que possa adentrar o real e viajá-lo, e neste sentido, torná-lo corpo.

A percepção encontra-se entre o corpo e a imagem e a afecção seria a entrada da imagem no corpo-pensamento. A presentificação do desejo, na recriação da imagem, a rompe e fragmenta fazendo-a navegar por parcialidades existenciais do sujeito, ou por suas lembranças que são convocadas através da percepção. Para Bergson (1999, p. 31): “Por mais breve que se suponha uma percepção, com efeito, ela ocupa sempre, uma certa duração, e exige consequentemente, um esforço da memória, que prolonga uns nos outros, uma pluralidade de momentos." Não há percepção, portanto, que não esteja impregnada de lembranças. E, assim, não existe circunscrição exata entre matéria e memória; por isto, o corpo é imagem - somos imagem. Segundo o filósofo, a diferença paira na diferenciação de grau entre percepções e lembranças e viceversa. As percepções, ao serem modificadas em intensidade, tornam-se lembranças.

O jogo do corpo com as imagens pode ser pensado em ações de corte e costura: não se vê tudo; corta-se, gerando uma seleção e, em 
cada área de privação, oriunda do inextensivo, forma-se um intervalo entre o corpo e a matéria. Entretanto, aquilo que ficou, aquilo que veio do recorte transmuta-se com a costura destes fragmentos com a memória ou carga existencial que coincide com a duração imposta pela percepção: quando se corta, já floresce.

Cada lembrança é um ponto da tessitura na teia da experiência com o fora que transmuta matéria em memória. Para Bergson (1999), a percepção é a matéria retirada do que não convém ao corpo vindo a limitar a imagem e, na criação deste território, desenha-a com imagens anteriores remetendo ao passado. J ogo de espelhos, sobreposição.

Tais desenhos inventam o corpo através das diferenciações: vamos do corpo à imagem, do corpo a outros corpos e, através de tais trânsitos na matéria, o corpo vai ganhando extensão variável e investindo-se de mundo. Assim, a matéria torna-se desenorme cabendo no espaço do corpóreo que, em suas mil e muitas memórias, cria alquimias das faces do mundo. Então, nos desigualamos.

Enfim, o corpo captura a imagem no tempo e o instante no encontro dos movimentos da memória com os movimentos do exterior. É o encontro que se registra e não seus objetos. É impossível congelar a imagem para estudar sua natureza sob todos os ângulos, isentandose de implicação. Não vemos com os olhos, vemos com a memória. Perante imagens, segue-se o movimento das ecceidades que se conectam e produzem desvios ao invés de regras e, a partir daí, novos movimentos: um terceiro que se produz, podendo conectar-se a outros e produzir ainda outros, infinitamente. A imagem é sugada pela memória, vindo a fazer parte da história de uma vida e da história de nosso mundo. A memória é um reservatório sempre movimentado e re-significado pela última imagem, pelo último encontro, pela última exposição.

Se pensássemos em termos puros ou no ultrapassamento do corpo, a percepção sem mediação seria igual à matéria e a memória pura igual a todo o passado. E, se não ultrapassássemos centralizando no corpo, este seria centro de virtualização/objetivação da imagem, propagador de misturas, atrator conectivo através de marcas passadas. Por outro lado, a imagem, da mesma forma, virtualiza o passado. O corpo faz a imagem diferir de si e vice-versa. Estes movimentos são produzidos de forma infinitesimal na conjugação de subjetividade e objetividade.

As diferenças em pauta relacionam-se ao conceito de duração que é o que difere, mas que difere de si ou o poder de diferenciação de qualidade de todas as coisas e dela própria alterando-se. A duração é o meio no qual se operam as mudanças de natureza vindo a ancorar as multiplicidades que em mistura iram formar os outros do si. Aqui, a correspondência não é entre o corpo e a imagem e sim entre o corpo e ele mesmo em processualidade nos movimentos de contração da matériaimagem.

Outra processualidade importante para a presente discussão situa-se entre matéria e duração: a diferença de natureza pulsante, na duração, está ligada às diferenças de proporção e colocação da matéria-imagem em seu trânsito no espaço.

A imagem é uma possibilidade de abandonarmos a própria duração partindo da nossa e deixando-a para trás, como alavanca do reconhecimento da presença de durações diversas. Acreditamos ser possível o abandono da própria duração, na medida em que, no encontro com a imagem somos diferidos daquilo que éramos criando uma coexistência temporal com os instantes criados por tal acoplamento. Entraríamos, pois, em devir com a imagem. Para Deleuze e Guattari (1997, p. 18): “O devir nada produz por filiação. O devir é da ordem da aliança. Se a evolução comporta verdadeiros devires, é no vasto domínio das simbioses que coloca em jogo seres de escalas e reinos inteiramente diferentes, sem qualquer filiação possível." Então, estamos falando do devirimagem no homem e suas durações coextensivas, a referência é em relação ao instante que nos tornamos a imagem que vemos. Entre dois corpos por mais juntos que estejam existe um espaço, um entre que faz sentir, um intervalo de espaço, uma breve abismo por onde o mundo pulsa. Neste ínterim se produz o devir que cria o ente mestiço e a possibilidade de sermos as coisas, sermos os Outros. Nos interstícios da matéria e entre os corpos poderemos ser tomados por forças que fazem com que nos tornemos elas mesmas.

Ainda no campo do tempo, a imagem opera o passado e o presente nos seguintes sentidos: faz passar o presente, conserva o passado e, concomitantemente, também o desfigura. O 
passado mantém, em parte de sua composição, um caráter intocado, o das lembranças puras que vão ser revertidas, no agora, em imagens lembrança.

Consequentemente, poderíamos rever o conceito de lembrança e colocá-la no tempo presente. A lembrança é presente! Avançando um pouco mais nas complicações do tempo, poderíamos dizer que o presente é a ponta ou afunilamento do passado que toca o corpo pela via imagética. A imagem convoca e seduz o passado. O passado, então, seria uma grande imagem contraída em tons, enquadramentos, contrastes e brilho de pequena lágrima na pele. O passado pronto para avançar pelo suceder das cenas imediatas. Em qual canto do passado esconde-se engenhosamente a lembrança recém-nascida? Em qual imagem a tocarei?

A imagem, finalmente, contém impulso de vida e o corpo em sua entrega ao acaso, que é nosso destino, flui em mares de imagens e, assim, a vida vai resistindo, tornando-se outra quase inapreensível, explodindo em multiplicações para realizar-se. As diferenciações podem, em parte, tornarem-se conscientes e erigirem-se através do acontecimento da pesquisa e do conhecimento problematizando o visto e reanimando a matéria. Pensemos, pois a imagem como experiência do corpo e como travessia sem chegada ao real. Seguimos nesta travessia, não só vendo, mas produzindo imagens e, no cruzamento de fronteiras, poderemos fechar, momentaneamente, os olhos e sonhar com ardores criativos e, um certo colorido, para nossas pequenas mortes.

Não há um tempo de verdade ou de representação, mas um tempo de imanência, de ida e vinda do caos e de um inconsciente ativado pelo fora e sempre em processo e em meio.

As condições para que isto ocorra é o encontro expansivo entre corpos; o corpo imagético em mutação, os corpos em multidão criando e traçando, ocasionalmente, diferenças que apontam para certos usos singulares da expressão manifestando-se como produto final, como condição anterior ao processo e, como o processo como tal. Querer criar é a inclinação necessária para a experiência de resistência a representação e em cada desvio, afirma o encorajamento para um olhar menor instigando o fortalecimento da máquina imagética em sua grandeza instituinte.

\section{Referências}

BERGSON, Henry. Matéria e Memória: ensaio sobre a relação do corpo com o espírito. São Paulo: Martins Fontes, 1999.

DELEUZE, Gilles. Crítica e Clínica. São Paulo: Ed. 34, 1997.

DELEUZE, Gilles. A I Iha Deserta: e outros textos. Edição preparada por David Lapoujade; organização da edição brasileira e revisão técnica de Luiz B.L. Orlandi. São Paulo: Iluminuras, 2006.

DELEUZE, Gilles.; GUATTARI, Felix. Kafka: para uma literatura menor. Rio de Janeiro: Ed. Assírio \& Alvim, 2003.

DELEUZE, Gilles.; GUATTARI, Felix. Mil Platôs: capitalismo e esquizofrenia. Rio de Janeiro: Ed. 34, 1995. V. 1.

DELEUZE, Gilles.; GUATTARI, Felix. Mil Platôs: capitalismo e esquizofrenia. Rio de Janeiro: Ed. 34, 1997. V. 4.

GUATTARI, Felix; ROLNIK, Suely. Micropolítica: cartografias do desejo. Petrópolis: Vozes, 1993.

Recebido em julho de 2008

Aceito para publicação em setembro de 2008

Patrícia Kirst

Doutoranda na Pós Graduação em Informática na Educação pela Universidade Federal do Rio Grande do Sul (PPGIE/UFRGS). pgomes.voy@terra.com.br

Tânia Mara Galli Fonseca

Psicóloga, docente nos programas de pós-graduação em Informática na Educação e em Psicologia Social e Institucional da Universidade Federal do Rio Grande do Sul (UFRGS).

tfonseca@via-rs.net 